\title{
Getting the numbers right in Africa - a tribal solution
}

I $\mathrm{t}$ often seems that the health care numbers and vital statistics in Africa are as hazy as the sun on the horizon.

Medical statistics, for example, can come with staggering margins of error. The World Health Organization notes in "2011 World Health Statistics" that "there are considerable uncertainty ranges for many countries due to limitations in data availability, quality and timeliness. Uncertainty ranges in estimated all-cause mortality for 2008 vary from $\pm 1 \%$ for high-income countries to +15-20\% for sub-Saharan Africa."

Health officials contend that they have no option but to rely on the information available, which is usually only hospital data. But in many sub-Saharan African countries, that's almost deceptive, as many births and deaths, as well as medical services, occur in nonhospital settings.

But Malawi appears to be pointing the way toward harder, more accurate numbers by creating a data collection system that makes "village headmen" responsible for collecting vital data.

"We have given the headmen of the villages registers," says Bester Mandere, commissioner of the district of Thyolo, home to about 600000 of Malawi's 13 million residents, an estimated $12 \%$ of whom are HIV-positive. "If there are births in the communities, they record them. If there are deaths too, they record in the register."

The Thyolo district is divided into 12 administrative areas called traditional authorities. Each is headed by a chief and composed of several villages. Each village, in turn, is led by a headman. A group of 6-10 villages is led by a group headman. In total, the district has 423 village headmen and 65 group headmen.

"The chiefs and the headmen are better placed to know what happens in their communities and to report them," says Geoffrey Kumbuyo, a district officer in Thyolo. "Normally, in terms of reporting [of births and deaths], things have to

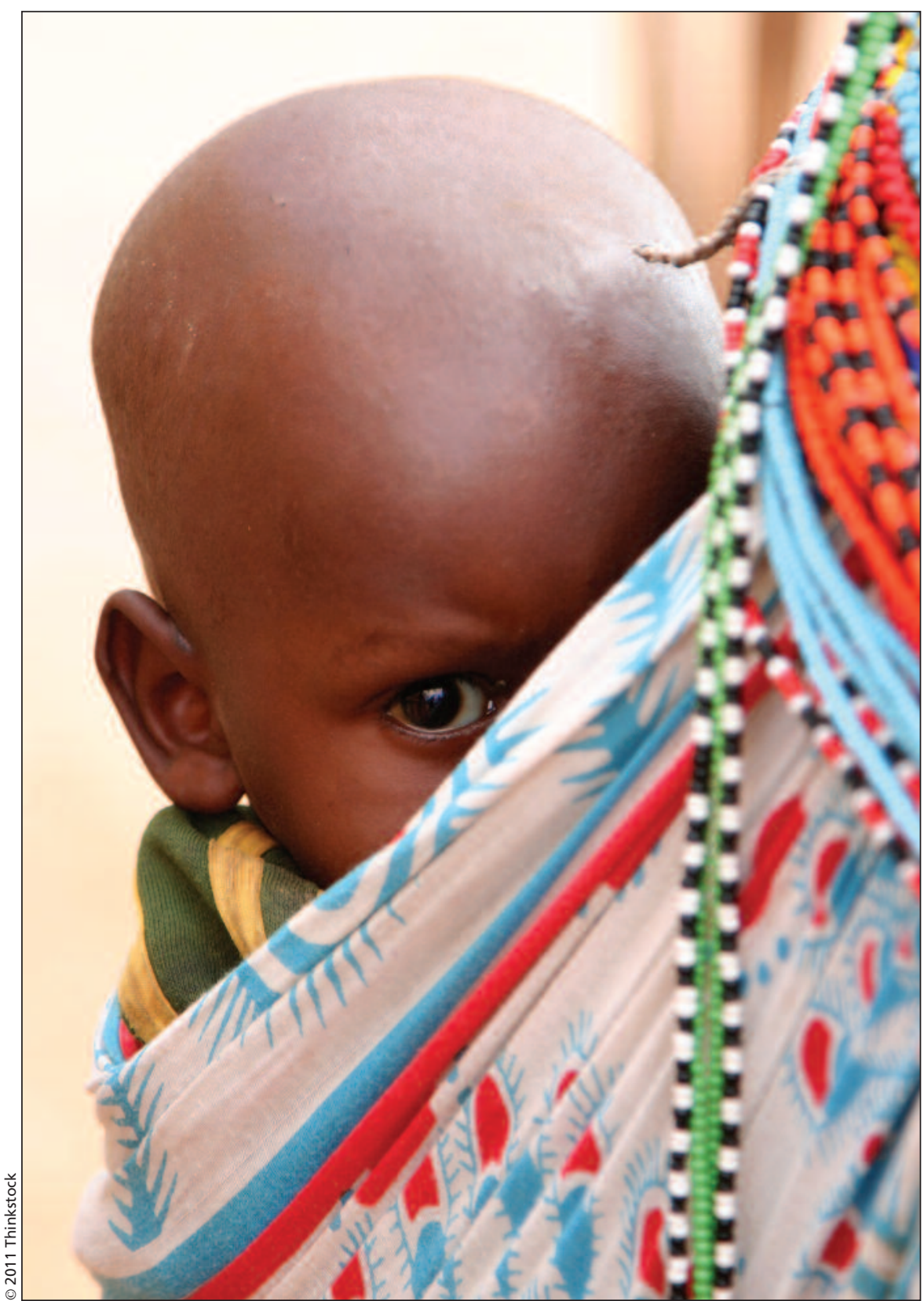

In some sub-Saharan African countries, relying only on hospital data for medical statistics, such as number of children born in a village, is not enough because many births occur outside of hospitals.

come from the group village headmen to the chiefs of the traditional authorities. Then the chiefs of the authorities report to the district commissioner.'

Cultural traditions in Malawi make such data collection possible, says Anthony Harries, honourary professor of medicine at the London School of Hygiene and Tropical Medicine in the United Kingdom, where he now lives, and a former resident of Malawi for more than 20 years.

Village headmen keep a record of births and deaths in part because no 
one can be buried in a village unless the headman gives approval. When people die, they must be sent to their home villages for burial. Village headmen must provide periodic updates to chiefs because the latter must have accurate information when, for example, arbitrating property disputes after someone dies.

The informal system of keeping statistics has been around for decades and used for tax purposes, as well as in determining household eligibility for food aid and agricultural subsidies.

Historically, village registers were little more than hardcover exercise books, but in 2007 the government of Malawi began to formalize the system, requiring district assemblies to develop registers that included such data as date of birth, name of parents, birth certificate number and cause of death.

Though the goal is to reach all districts of Malawi, implementation is not yet nationwide, Harries says. So far, about half the country is utilizing the system.

Several challenges remain in using the data to monitor and measure health interventions, as well as progress toward health-related millennium development goals such as a reduction in mortality rates, says Rony Zachariah, operational research coordinator for Médecins Sans Frontières, who is based in Luxembourg but has been working in Malawi for the past 10 years. They include a lack of political will, the absence of a formal link between civic authorities and the health system and the difficulty of determin- ing causes of death in rural Africa because of a lack of pathologists.

Zachariah suggests that community health workers be trained to monitor births and deaths in rural Africa and to work with village headman to help capture data, including interviews with community members to identify potential causes of death in a sort of verbal autopsy.

"We need to move forward on vital registration. Otherwise it would be difficult to really measure the impact of health-level interventions," Zachariah says. To achieve that, "we need to make use of the existing systems in rural Africa." - Bernard Appiah, College Station, Tex.

CMAJ 2011. DOI:10.1503/cmaj.109-3941 